\title{
$\angle$ Research Square \\ The effect of adding curcumin to sodium valproate in treatment of patients with bipolar disorder in the acute phase of mania: a clinical trial.
}

\section{Farzad Akbarzadeh}

Mashhad University of Medical Sciences Ghaem Hospital

Nabahat Niksun

Mashhad University of Medical Sciences

Fatemeh Behdani

Mashhad University of Medical Sciences Ghaem Hospital

Amir Hoshang Mohammadpour

Mashhad University of Medical Sciences

Mahmoudreza Jaafari

Mashhad University of Medical Sciences

Alireza Ebrahimi

Mashhad University of Medical Sciences

Zahra rajai ( Rajaeiz961@mums.ac.ir)

Mashhad University of Medical Sciences https://orcid.org/0000-0002-7543-532X

Tayebeh Hosseini

Mashhad University of Medical Sciences

\section{Research}

Keywords: crucumin, clinical trial, sodium valproate, bipolar mood disorder

Posted Date: January 3rd, 2020

DOI: https://doi.org/10.21203/rs.2.19925/v1

License: (c) (i) This work is licensed under a Creative Commons Attribution 4.0 International License.

Read Full License 


\section{Abstract}

Background: Inflammatory processes in the brain play an important role in etiopathogenesis of many psychiatric disorders including, bipolar mood disorder (BMD) as a life-long episodic disease. An inefficient therapeutic intervention especially for resistant cases makes the necessity of doing more precise investigation to find out new therapeutic approaches apparent. This double-blind study aims to investigate the effect of Crucumin as anti-inflammatory herbal based drug in the treatment of BMD.

Results: 78 patients who met the Diagnostic and Statistical Manual of Mental Disorders (DSM-V) criteria for BMD screening to participate in the trial. The participants included 32 patients in the placebo group receiving sodium valproate and crucumin and 38 patients in the control group receiving placebo and sodium valproate. At the beginning of the study and weeks 1, 2, 4 the patients were assessed by a psychiatrist using Young mania score (YMRS). Fifty four patients completed the trial. Mean age in patients group was $36.28 \pm 10.73$ and in control group was $32.42 \pm 9.60$.Clinical characteristics of the patients, such as age, did not differ between groups $P$ value $\geq 0.05$. Results showed the process of changes were significant different in both group. The results showed that the changes in the resultss of YMRS, MMSE and CGI scores were significant in each group ( $P$ value $\leq 0.001)$, but no significant difference has been detected between the two groups $(p \geq 0.05)$.

Conclusions: this study suggested that crucumin cannot be an effective adjuvant agent in management of patients with BMD under treatment with sodium valproate.

\section{Background}

Bipolar mood Disorder (BMD) is a life-long episodic disease described by changing in person's mood between mania and depression. During mania episode, effective and timely diagnostic and therapeutic interventions is required to minimize the disorder's harmful individual and inter personal side effects which could easily interrupted an individual's normal life.1

As mentioned, doing researches to find out an effective medical treatment seems to be necessary while preserving various dimensions of personal and social life of patients from disorder's full influenced cost.

Psychopharmacological treatments are the first line for treating this disorder. So far, mood stabilizers including carbamazepine, sodium valproate and some types of antipsychotics have been used to treat acute phase of mania. 1

concerning the bipolar disorder's prevalence (1.5\%), disorder's suicidal rate (10-20\%), high recurrence of this disorder ,half effectiveness of single-drug therapy, as well as considering inefficient therapeutic interventions such as drug augmentation for managing resistant to response cases; The necessity of doing more precise investigation to find out new therapeutic approaches is apparent .1 
Various studies have found that serum BDNF levels decreased in bipolar disorder (2). Curcumin like the well-known treatments of this disorder (lithium, etc and atypical antipsychotics) can increase BDNF levels.(3-5)

There is much evidence that oxidative stress mechanisms have been involved in bipolar disorder $(6,7)$. In this way, increasing ROS production lead to the lack of antioxidant mechanisms resulting in apoptosis, necrosis and brain damage (6-9). Studies have shown that curcumin has antioxidant function which can reduce $\operatorname{ROS}(10,11)$

Inflammatory processes affect neurotransmitter function and neuronal plasticity $(12,13)$ which play a noteworthy role in the pathophysiology of neurodegenerative diseases (14). Increasing of CRP, inflammatory cytokines and TNF alpha occur in bipolar disorder can be reduced by curcumin $(15,16)$. There is also evidence about impairment of apoptosis in psychiatric diseases, which leads to an increase in cell death $(17,18)$. Curcumin can regulate these mechanisms $(19)$.

Since the ancient Persian medical texts have highlighted the anti-inflammatory effects of turmeric, many studies have been carried out on this subject. However, limited studies have been performed to evaluate its effects on dipolar disorder. The purpose of this study was to determine the effect of adding curcumin to sodium valproate in the treatment of patients with bipolar disorder in the acute phase of mania.

\section{Material And Method:}

This study is a double-blind clinical trial performed during $1396-1395$. Initially, 78 patients aged 18 to 50 years old diagnosed with bipolar mood disorder, based on DSM 5 criteria, And according to the inclusion criteria of current study, were participated in this study.

Inclusion criteria:

- The age of the subjects was 18 to 59 years old

- Diagnosis of bipolar-1 disorder with recent episode mania based on DSM-5 diagnostic criteria by Semi-structured interview done by a psychiatrist and diagnostic confirmation with a score of at least 20 of Young mania score (YMRS) (20)

- The absence of the diagnosis of schizophrenia, delirium, bulimia nervosa, anorexia nervosa, mental retardation, autism, substance abuse (at least 3 months ago), ADHD.

- No history of admission to the psychiatric ward during the past three months

- No history of seizure or epilepsy

- the absence of suicidal or homicidal risk during the psychiatric interview

- Women suspected to be pregnant will undergo a pregnancy test and, if positive, be excluded from the study.

- Lack of a history of susceptibility to sodium valproate or any herbal medicines. 
- Patients who have received other medications during the last two weeks prior to study or during the study, including mood stabilizer treatments that cannot stop them. The washout period will be considered based on the medication's half-life for patients receiving drugs with a long half-life.

A full interview was conducted for each patient by a psychiatric resident (based on inclusion and exclusion criteria) and diagnostic suspicion cases were excluded from the study. The informed consent was obtained from eligible patients. (Or their legal guardians)

Patients who agreed to participate in our trial were randomly assigned into two groups using randomized number table. Patients in the intervention group besides receiving sodium valproate (starting at a dose of $600 \mathrm{mg}$ / day and administrate up to $20 \mathrm{mg} / \mathrm{kg} /$ day or the highest dosage of the patient's tolerance), received curcumin drug while control group received placebo in addition to sodium valproate.

Placebo soft gels were made by the same manufacturer of soft curcumin gels, having the same size, color and smell. Soft curcumin gel has $40 \mathrm{mg}$ Nanomycesel, absorbed as equivalent to $500 \mathrm{mg}$ curcumin tablets.

Cases were evaluated at baseline, 1 week, 2weeks and 4 weeks after the prescription of the drugs using the clinical global impression (CGI) and young mania rating scale (YMRS).(20-22) MMSM (mini mental state examination) have been performed for cases at the end of the first and fourth weeks of treatment.

It should be noted that due to the lipophil nature of curcumin, the oral absorption of curcumin in common oral forms (powder, capsule and pill) is very low. In this study, soft gelatin capsules containing curcumin nanomicelles with the brand name Sina Curcumin was used. In the Sina Curcumin product, all curcumin is blocked in the hydrophobic section of curcumin nannies. These spherical nanomicelle particles have a particle size of about $10 \mathrm{~nm}$ and increase water solubility of curcumin. After oral administration, soft gel capsules containing curcumin nannies are disintegrate in the stomach acidic environment in less than 15 minutes. These nanomicelles remain for at least 6 hours in the acidic environment of stomach and do not eliminate and get to the small intestine intact.

Upon reaching the small intestine, nanomicelles facilitates the transfer of curcumin from the inert surficial water layer of the intestinal epithelial cells; which inhibits the absorption of lipid soluble compounds and increases the oral absorption of curcumin.

The side effects of drugs in each visit have been evaluated by psychiatric resident using a checklist and if necessary, the essential laboratory tests have been done under the psychiatrist's vision.

For describing the data, descriptive statistics including frequency tables, diagrams, and statistical indicators were used, and data analysis was done using SPSS software version 11.5.

To analyze the data, Kolmogorov-Smirnov test, Mann Whitney test, independent T-test, Fisher's exact test and chi-square were applied. A p-value less than 0.05 were taken as mean statistical significance. To 
control and determine the effect of confounding variables in case of heterogeneity between two groups, appropriate statistical tests such as covariance or logistic regression were used.

Since this research was conducted for the first time and no similar research to ours has been done yet, with regard to the goals mentioned so far, sample size calculations cannot be used by statistical formulas. Therefore, this study was done as a preliminary study with a sample size of 20 people in each group, that is, a total of 40 cases.

\section{Results:}

78 cases were screened for participating in this study among those 8 cases who were reluctant to participate in the study, 8 cases for discontinuing sodium valproate, 2 patients due to change of the diagnosis or therapeutic regime and 4 cases due to lack of cooperation has been excluded from the study, while 54 cases continued The study till the end. (Fig. 1 includes the consort flow diagram of the trial).As you can see Table 1 includes Patient's demographic data comparison between two groups.

\begin{tabular}{|c|c|c|}
\hline & Intervention group & Control group \\
\hline \multirow[t]{2}{*}{ sex } & Female :12 & Female :9 \\
\hline & Male :23 & Male :6 \\
\hline Age & $36.28 \pm 10.73$ & $32.42 \pm 9.60$ \\
\hline \multirow{3}{*}{$\begin{array}{l}\text { History of } \\
\text { admission }\end{array}$} & $\leq 1: 5$ & $\leq 1: 10$ \\
\hline & $2-3: 16$ & $2-3: 13$ \\
\hline & $\geq 3: 7$ & $\geq 3: 3$ \\
\hline $\begin{array}{l}\text { Medications } \\
\text { history }\end{array}$ & $\begin{array}{l}\text { risperidone: } 10 \text {; alprazolam: 8; } \\
\text { olanzapin: 4, lithium:5, Quetiapine:1 }\end{array}$ & $\begin{array}{l}\text { risperidone: 9; alprazolam: 2; olanzapin: } \\
\text { 8, lithium:2, Quetiapine:5 }\end{array}$ \\
\hline \multirow{2}{*}{$\begin{array}{l}\text { Family } \\
\text { history }\end{array}$} & Yes:10 & Yes:15 \\
\hline & No:18 & No:11 \\
\hline \multirow{2}{*}{$\begin{array}{l}\text { History of } \\
\text { inflammation }\end{array}$} & Yes:3 & Yes:2 \\
\hline & No:25 & No:24 \\
\hline \multirow{2}{*}{$\begin{array}{l}\text { Past } \\
\text { psychiatric } \\
\text { history }\end{array}$} & Yes:6 & Yes:10 \\
\hline & No:22 & No:16 \\
\hline
\end{tabular}

Table 1. Comparing the Characteristics of patients in the two groups 
Table 2

Average MMSE scores in both the intervention and control group

\begin{tabular}{|lll|}
\hline & $\begin{array}{l}\text { Intervention group } \\
\mathbf{N}=\mathbf{2 8}\end{array}$ & $\begin{array}{l}\text { Control group } \\
\mathbf{N}=\mathbf{2 6}\end{array}$ \\
\hline Baseline & $(4.80 \pm) 22.44$ & $20.92( \pm 4.15)$ \\
\hline Week 4 & $(4.55 \pm) 24.60$ & $23.53( \pm 3.78)$ \\
\hline P value & 0.000 & 0.000 \\
\hline
\end{tabular}

After 4 weeks of trial the MMSE score showed a significant difference in each group. (P value: 0.00) To compare these changes between the two groups, the Mann-Whitney test was used and no significant difference was detected. (P value: 0.68 ) (Table 2 )

Table 3

Average Young mania rating scores (YMRS) in both intervention and control groups.

\begin{tabular}{|lll|}
\hline & $\begin{array}{l}\text { Intervention group } \\
\mathbf{N}=\mathbf{2 8}\end{array}$ & $\begin{array}{l}\text { Control group } \\
\mathbf{N}=\mathbf{2 6}\end{array}$ \\
\hline Baseline & $(6.13 \pm) 26.32$ & $26.57( \pm 5.19)$ \\
\hline Week 1 & $(6.78 \pm) 19.21$ & $21.57( \pm 6.11)$ \\
\hline Week 2 & $(7.08 \pm) 14.53$ & $15.50( \pm 6.88)$ \\
\hline Week 4 & $(6.27 \pm) 7.32$ & $7.96( \pm 6.58)$ \\
\hline
\end{tabular}

Although the descending Progression of young scores in each group was significant (p-value: 0.00), No significant difference between the two groups was considered after 4 weeks. (P value: 0.64 )(Table 3 )

Table 4

Average CGI scores in both intervention and control groups.

\begin{tabular}{|lll|}
\hline & $\begin{array}{l}\text { Intervention group } \\
\mathbf{N}=\mathbf{2 8}\end{array}$ & $\begin{array}{l}\text { Control group } \\
\mathbf{N}=\mathbf{2 6}\end{array}$ \\
\hline Baseline & $1.00( \pm 0.00)$ & $1.00( \pm 0.00)$ \\
\hline Week 1 & $1.71( \pm 0.65)$ & $1.53( \pm 0.50)$ \\
\hline Week 2 & $2.53( \pm 0.63)$ & $2.63( \pm 0.65)$ \\
\hline Week 4 & $3.50( \pm 0.83)$ & $3.53( \pm 0.70)$ \\
\hline
\end{tabular}


Considering the significant ascending Progression of CGI scores in each group ( $p$-value: 0.00), there was no significant difference between the two groups' results after 4 weeks. (P value: 0.93)(Table 4)

Table 5

Average CGI scores in both intervention and control groups.

\begin{tabular}{|lll|}
\hline & $\begin{array}{l}\text { Intervention group } \\
\mathbf{N}=\mathbf{2 8}\end{array}$ & $\begin{array}{l}\text { Control group } \\
\mathbf{N}=\mathbf{2 6}\end{array}$ \\
\hline Response to treatment & $24(84.7 \%)$ & $20(76.9 \%)$ \\
\hline Without response to treatment & $4(14.3 \%)$ & $6(23.1 \%)$ \\
\hline
\end{tabular}

While the percentage of response to treatment in the intervention group was higher than control group, Fisher's exact test didn't confirm any significant difference between two groups. (P-value: 0.49)(Table 5)

Table 6

Evaluating the Subsidence of symptoms in both intervention and control groups.

\begin{tabular}{|lll|}
\hline Subsidence of symptoms & $\begin{array}{l}\text { Intervention group } \\
\mathbf{N}=\mathbf{2 8}\end{array}$ & $\begin{array}{l}\text { Control group } \\
\mathbf{N}=\mathbf{2 6}\end{array}$ \\
\hline Yes & $22(78.6 \%)$ & $19(73.1 \%)$ \\
\hline No & $6(21.4 \%)$ & $7(26.90 \%)$ \\
\hline
\end{tabular}

In both groups, more than half of the patients have reported the subsidence of symptoms which was higher in the intervention group comparing to the other one, But as well as response to treatment results, the Fisher's exact test was not meaningful between two groups.( $P$ value: 0.75$)$ (Table 6)

Table 7

The frequency of the severity of disease and MMSE score in both intervention and control groups at the beginning of the study.

\begin{tabular}{|llll|}
\hline & $\begin{array}{l}\text { Intervention group } \\
\mathbf{N}=\mathbf{2 8}\end{array}$ & $\begin{array}{l}\text { Control group } \\
\mathbf{N}=\mathbf{2 6}\end{array}$ & P Value \\
\hline Average disease severity score & $26.32( \pm 6.13)$ & $26.57( \pm 5.19)$ & 0.58 \\
\hline Average MMSE score & $22.42( \pm 4.80)$ & $20.92( \pm 4.15)$ & 0.56 \\
\hline
\end{tabular}

Comparing the severity of the disease and MMSE score in both groups at the baseline didn't show any significant difference based on Fisher's exact test. (Table 7)

\section{Discussion:}


Bipolar Disorder (BMD) is a life-long episodic disease characterized by changing in person's mood between mania and depression. During mania episode, effective and timely diagnostic and therapeutic interventions is required to minimize the disorder's harmful individual and inter personal side effects which could easily interrupted an individual's normal life. Many patients with this disorder often experience recurrent episodes throughout their lives if not receiving proper treatment and follow up. The acute phase of mania episode leads to unpleasant effects on the patients' mental status \& his family as well as its effects on the progression and prognosis of the disease itself. The costs that the patient imposes on the family and society during the acute phase of the disease, directly and indirectly, is much greater than the cost of proper and timely treatment of the disease. 1

As mentioned, doing researches to find out an effective medical treatment seems to be necessary while preserving various dimensions of personal and social life of patients from disorder's full influenced cost.

Psychopharmacological treatments are the first line for treating this disorder. So far, mood stabilizers including carbamazepine, sodium valproate and some types of antipsychotics have been used to treat acute phase of mania.1 The lack of proper response to existing drugs among significant numbers of patients, makes inventing new medicines for treating these patients as well, a main concern for many scientist.

The results of laboratory researches demonstrated that the increased activity of the hypothalamus axis in mood disorders including bipolar disease leads to changes in the level of many inflammatory cytokines .23

Regarding the role of inflammation in the pathophysiology of the bipolar disease, several studies, indicated the efficacy of anti-inflammatory drugs in affected patients. Some studies show that curcumin inhibits the expression of COX2 and the production of cytokines such as interferon-gamma and interleukin-6 which results in inhibiting the inflammatory responses.

Part of the anti-inflammatory effects of turmeric may be due to the inhibitory effects of curcumin on the activity of the hyaluronidase enzyme.24

In a review study done by Brietzke and coleague in 2013, evaluated the curcumin's anti-inflammatory and anti-oxidant properties. Discussing its therapeutic prospective in Bipolar disorder they find out that this agent is notably affecting on depressive symptoms and cognitive impairment. Although they suggested further clinical trial to be done for supporting this issue, the demonstrated that many CAM (complementary and alternative medicines) turned out to be ineffective at best and damaging at worst in treating Bipolar disorder. 32

Now a day the issue of complementary usage of herbal and ancient medicine in modern practice has become the topic of the day, thus many researchers try to use ancient herbal medicine in new pharmacological forms in order to find out a relief pathway in treating disorders. The purpose of this 
study was to explore whether curcumin as widely-mentioned anti-inflammatory herbal based drug, has an effect on bipolar disorder treatment or not.

The results of our study showed significant reduction progress in young mania score after 4 weeks of receiving the curcumin versus placebo in each group. Although the intervention group shows a higher response to treatment and subsidence of symptoms, this difference was not statistically significant comparing to control group. Also, the results of patients' overall function and cognition (CGI and MMSE scores) after 4 weeks showed a significant improvement in each group, but this improvement was not statistically meaningful between the two groups.

Studies have claimed curcumin's anti-inflammatory effects in deactivating free radicals and its anticancer effects have been proven which are mainly due to its effect on intracellular enzymes \& inhibition of signaling pathways at various levels. These effects of curcumin are often dose and environmentalcondition dependent.24-26

The curcumin therapeutic effects appear to be because of its neuroprotective and antioxidant effects which increase the level of neurotrophic factors. Given the low bioavailability of the drug, it seems necessary to increase the dose. Concerning other studies, a dose of $500 \mathrm{mg}$ per day which was used in ours also seems to be a low dose of curcumin. $30-27$

In the present study, the drug dosage was much lower than other studies which may also affect the patients' lack of response. In most studies, the recommendation is to start with a dose of $20 \mathrm{mg}$ based on weight and increase to a dose of $80 \mathrm{mg}$ per $\mathrm{kg}$, which is about $1500 \mathrm{mg}$ per day (31)

\section{Conclusion:}

The results of our study showed higher response to treatment, subsidence of symptoms and improving in patients' overall function and cognition after 4 weeks of receiving the Curcumin but this improvement was not statistically meaningful. According to our study Curcumin add-on therapy doesn't seem effective in treating acute phase of mania in patients with bipolar disorder.

\section{Limitations}

The limited small sample size and the fixed dosage of the curcumin were our study's constraints. We suggested the use of higher doses of curcumin which is better to be administrated according to the curcumin serum level, in the future studies.

\section{Declarations}

Ethics approval and consent to participate: 
All participants voluntarily and consciously participated in our study. After obtaining the scientific approval by the psychiatric Department, the proposal of this thesis research was offered to the Ethics Committee of Mashhad University of Medical Sciences.

Indeed, the participants were completely informed about the aim and the method of our study, and an informed consents have been taken orally and written in patients' native language (Persian) prior to the study.All participants' were assured that their information was kept confidential and they were able to leave the study at any time. Furthermore, patients who needed urgent intervention or suspected to intensifying symptoms by the treatment used in our research, were excluded from the study.

Consent for publication:

"Not applicable"

Availability of data and materials:

The datasets used and/or analysed during the current study are available from the corresponding author on reasonable request.

Competing interests:

The authors declare that they have no competing interests.

Funding

No funding was received.

Authors' contributions

FA and FB designed the study and supervised the group.AHM and $\mathrm{MJ}$ designed the placebo and Curcumin drug. TH, ZR and NN screened and supervised in case finding and managing the RCT. NN and $A E$ analyzed and interpreted the patient's data. ZR and FA are the major contributors in writing the manuscript. All authors read and approved the final manuscript

Acknowledgements

Not applicable

\section{References}

1. Kaplan BJ. Kaplan and Sadock's Synopsis of Psychiatry. Behavioral Sciences/Clinical Psychiatry. Tijdschrift voor Psychiatrie. 2016;58(1):78-9.

2. Fernandes BS, Gama CS, Ceresér KM, Yatham LN, Fries GR, Colpo G, et al. Brain-derived neurotrophic factor as a state-marker of mood episodes in bipolar disorders: a systematic review and meta- 
regression analysis. Journal of psychiatric research. 2011;45(8):995-1004.

3. Hu Y, Yu X, Yang F, Si T, Wang W, Tan Y, et al. The level of serum brain-derived neurotrophic factor is associated with the therapeutic efficacy of modified electroconvulsive therapy in Chinese patients with depression. The journal of ECT. 2010;26(2):121-5.

4. de Sousa RT, van de Bilt MT, Diniz BS, Ladeira RB, Portela LV, Souza DO, et al. Lithium increases plasma brain-derived neurotrophic factor in acute bipolar mania: a preliminary 4-week study. Neuroscience letters. 2011;494(1):54-6.

5. Xu F, Plummer MR, Len G-W, Nakazawa T, Yamamoto T, Black IB, et al. Brain-derived neurotrophic factor rapidly increases NMDA receptor channel activity through Fyn-mediated phosphorylation. Brain research. 2006;1121(1):22-34.

6. Sun $X$, Wang J-F, Tseng M, Young LT. Downregulation in components of the mitochondrial electron transport chain in the postmortem frontal cortex of subjects with bipolar disorder. Journal of Psychiatry and Neuroscience. 2006;31(3):189.

7. Andreazza AC, Kauer-Sant'Anna M, Frey BN, Bond DJ, Kapczinski F, Young LT, et al. Oxidative stress markers in bipolar disorder: a meta-analysis. Journal of affective disorders. 2008;111(2):135-44.

8. Lennon S, Martin S, Cotter T. Dose-dependent induction of apoptosis in human tumour cell lines by widely diverging stimuli. Cell proliferation. 1991;24(2):203-14.

9. Berk M, Kapczinski F, Andreazza A, Dean O, Giorlando F, Maes M, et al. Pathways underlying neuroprogression in bipolar disorder: focus on inflammation, oxidative stress and neurotrophic factors. Neuroscience \& biobehavioral reviews. 2011;35(3):804-17.

10. Ak T, Gülçin İ. Antioxidant and radical scavenging properties of curcumin. Chemico-biological interactions. 2008;174(1):27-37.

11. Masuda T, Hidaka K, Shinohara A, Maekawa T, Takeda Y, Yamaguchi H. Chemical studies on antioxidant mechanism of curcuminoid: analysis of radical reaction products from curcumin. Journal of agricultural and food chemistry. 1999;47(1):71-7.

12. Trakhtenberg EF, Goldberg JL. Neuroimmune communication. Science. 2011;334(6052):47-8.

13. Yirmiya R, Goshen I. Immune modulation of learning, memory, neural plasticity and neurogenesis. Brain, behavior, and immunity. 2011;25(2):181-213.

14. Dean B. Understanding the role of inflammatory-related pathways in the pathophysiology and treatment of psychiatric disorders: evidence from human peripheral studies and CNS studies. International Journal of Neuropsychopharmacology. 2011;14(7):997-1012.

15. Goldstein BI, Kemp DE, Soczynska JK, Mclntyre RS. Inflammation and the phenomenology, pathophysiology, comorbidity, and treatment of bipolar disorder: a systematic review of the literature. The Journal of clinical psychiatry. 2009;70(8):1078-90.

16. Kandhare AD, Raygude KS, Ghosh P, Ghule AE, Bodhankar SL. Therapeutic role of curcumin in prevention of biochemical and behavioral aberration induced by alcoholic neuropathy in laboratory animals. Neuroscience letters. 2012;511(1):18-22. 
17. Dodd S, Maes M, Anderson G, Dean OM, Moylan S, Berk M. Putative neuroprotective agents in neuropsychiatric disorders. Progress in Neuro-Psychopharmacology and Biological Psychiatry. 2013;42:135-45.

18. Clay HB, Sillivan S, Konradi C. Mitochondrial dysfunction and pathology in bipolar disorder and schizophrenia. International Journal of Developmental Neuroscience. 2011;29(3):311-24.

19. RAMACHANDRAN C, RODRIGUEZ S, RAMACHANDRAN R, Nair PR, FONSECA H, KHATIB Z, et al. Expression profiles of apoptotic genes induced by curcumin in human breast cancer and mammary epithelial cell lines. Anticancer research. 2005;25(5):3293-302.

20. Barekatain M, Tavakoli M, Molavi H, Maroufi M, Salehi M. Standardization, reliability and validity of the Young Mania Rating Scale. Psychology. 2007;11(2):150-66.

21. Busner J, Targum SD. The clinical global impressions scale: applying a research tool in clinical practice. Psychiatry (Edgmont). 2007;4(7):28.

22. Haro J, Kamath S, Ochoa S, Novick D, Rele K, Fargas A, et al. The Clinical Global ImpressionSchizophrenia scale: a simple instrument to measure the diversity of symptoms present in schizophrenia. Acta Psychiatrica Scandinavica. 2003;107(s416):16-23.

23. Dowlati Y, Herrmann N, Swardfager W, Liu H, Sham L, Reim EK, et al. A meta-analysis of cytokines in major depression. Biological psychiatry. 2010;67(5):446-57.

24. Sharma R, Gescher A, Steward W. Curcumin: the story so far. European journal of cancer. 2005;41(13):1955-68.

25. Di Pierro F, Settembre R. Safety and efficacy of an add-on therapy with curcumin phytosome and piperine and/or lipoic acid in subjects with a diagnosis of peripheral neuropathy treated with dexibuprofen. Journal of pain research. 2013;6:497.

26. Bengmark S. Curcumin, an atoxic antioxidant and natural NFkB, cyclooxygenase-2, lipooxygenase, and inducible nitric oxide synthase inhibitor: a shield against acute and chronic diseases. Journal of Parenteral and Enteral Nutrition. 2006;30(1):45-51.

27. Wang R, Li Y-B, Li Y-H, Xu Y, Wu H-I, Li X-J. Curcumin protects against glutamate excitotoxicity in rat cerebral cortical neurons by increasing brain-derived neurotrophic factor level and activating TrkB. Brain research. 2008;1210:84-91.

28. Motterlini R, Foresti R, Bassi R, Green CJ. Curcumin, an antioxidant and anti-inflammatory agent, induces heme oxygenase- 1 and protects endothelial cells against oxidative stress. Free Radical Biology and Medicine. 2000;28(8):1303-12.

29. Wang R, Li Y-H, Xu Y, Li Y-B, Wu H-L, Guo H, et al. Curcumin produces neuroprotective effects via activating brain-derived neurotrophic factor/TrkB-dependent MAPK and PI-3K cascades in rodent cortical neurons. Progress in Neuro-Psychopharmacology and Biological Psychiatry. 2010;34(1):14753.

30. Thiyagarajan M, Sharma SS. Neuroprotective effect of curcumin in middle cerebral artery occlusion induced focal cerebral ischemia in rats. Life sciences. 2004;74(8):969-85. 
31. Kulkarni SK, Bhutani MK, Bishnoi M. Antidepressant activity of curcumin: involvement of serotonin and dopamine system. Psychopharmacology. 2008;201(3):435.

32. Brietzke E, Mansur RB, Zugman A. Is there a role for curcumin in the treatment of bipolar disorder? Med Hypotheses. 2013 May;80(5):606-12.

\section{Figures}

\section{Enrollment}

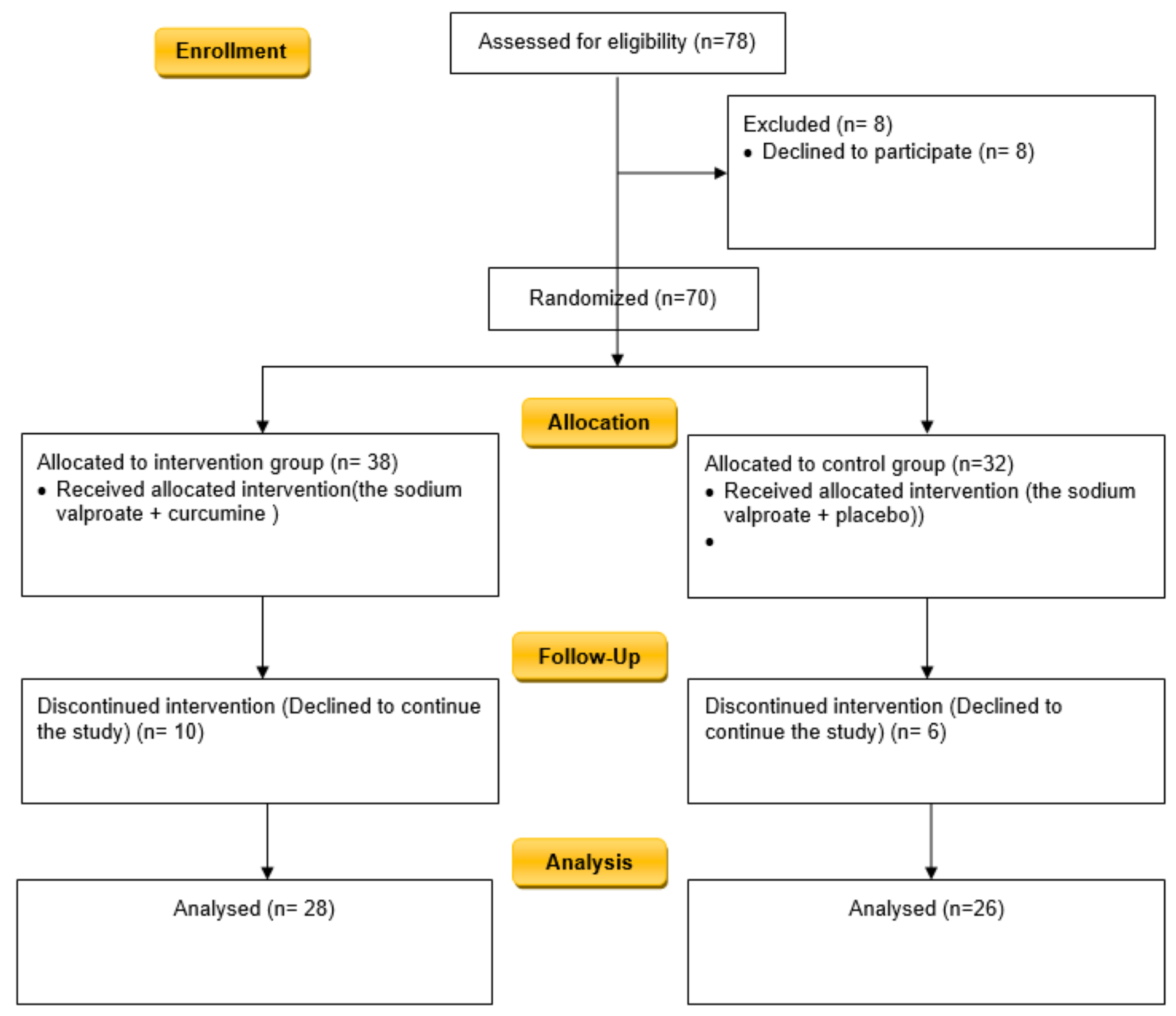




\section{Figure 1}

The consort flow diagram of the trial 